\title{
Letter to the Editor: Regarding "An Unusual Bilateral Duplication of the Suprascapular Vein and Its Relation to the Superior Transverse Scapular Ligament Revealed by Anatomage Table"
}

\author{
Azzat Al-Redouan, David Kachlik \\ Department of Anatomy, Second Faculty of Medicine, Charles University, Prague, Czech Republic \\ Correspondence: azzat.al-redouan@lfmotol.cuni.cz; Tel.: + 420257296 232; Fax.: + 420257296230
}

Received: 9 August 2020; Accepted: 9 December 2020

\section{Dear Editor,}

We read with interest the case presented by Panagouli et al. (1) concerning the unusual bilateral duplication of the suprascapular vein revealed by the Anatomage table. It is valuable to report findings on the cadavers incorporated into the Anatomage table because this resource is accessible worldwide. However, we would like to bring attention to the fact that the suprascapular vein (SV) may be rather more variable than the Panagouli et al. (2019) report states.

The SV is rather variable. It is not unusual to find the SV duplicated (2-5) and its site of drainage is variable as well (6). A duplicated SV was reported in 30 out of 103 cadaveric specimens of Korean origin (29.7\%) by Yang et al. in 2012 (2) and in 9 out of 88 cadaveric specimens of Polish origin (12.2\%) by Jezierski et al. 2016 (3). Furthermore, Podgorski et al. (2014) demonstrated detailed observations on the SV around the suprascapular notch (SSN) area. They reported 35 out of 60 selected dissections exhibiting variable suprascapular vascular arrangements. Twenty SSNs showed a duplicated SV, while 15 featured a triplicated SV. They proposed denominating the vein passing within the SSN by the term "suprascapular notch vein" on the basis of the fact that its course was distinguishably duplicated in 11 specimens (4).
The SV was found to drain into the external jugular vein in $60 \%$ of cases, and in the remaining cases it drained into the subclavian vein and into some other veins (6).

Regarding SV involvement in suprascapular nerve entrapment, it is not a definite risk factor. An existing SV within the SSN does not necessary reduce the space to a critical point, and it may rather serve as a protective cushion for the suprascapular nerve against the bony margins of the SSN during dynamic movements $(3,5)$.

In conclusion, we endorse reporting this variant structure in a cadaver used by multiple global users via the Anatomage table. Indeed, this report will draw attention to SV variability. However, we emphasize that it is not an unusual case, and that a duplicated SV is rather common.

Acknowledgment: The authors would like to thank Adam Whitley, MD - Department of Anatomy, Second Faculty of Medicine, Charles University, for the proofreading. Also the authors would like to thank Prof. Alison Shaw, Ph.D - Department of anthropology, Oxford University, for the editing and linguistic corrections.

Funding support: This work was supported by the Grant Agency of Charles University [Grant number: GAUK No. 1720119].

Conflict of Interest: The authors declare that they have no conflict of interest. 


\section{References}

1. Panagouli E, Tsirigoti A, Kotsira G, Demesticha T, Skandalakis P, Troupis T, Filippou D. An Unusual Bilateral Duplication of the Suprascapular Vein and Its Relation to the Superior Transverse Scapular Ligament Revealed by Anatomage Table. Acta Med Acad. 2019;48(3):307-11.

2. Yang HJ, Gil YC, Jin JD, Ahn SV, Lee HY. Topographical anatomy of the suprascapular nerve and vessels at the suprascapular notch. Clin Anat. 2012;25(3):359-65.

3. Podgórski M, Sibiński M, Majos A, Stefańczyk L, Topol M, Polguj M. The suprascapular vein: a possible etiology for suprascapular nerve entrapment and risk of complication during procedures around the suprascapular foramen region. Orthop Traumatol Surg Res. 2014;100(5):515-9.
4. Jezierski H, Wysiadecki G, Sibiński M, Borowski A, Podgórski M, Topol M, et al. A quantitative study of the arrangement of the suprascapular nerve and vessels in the suprascapular notch region: new findings based on parametric analysis. Folia Morphol (Warsz). 2016;75(4):454-9.

5. Labetowicz P, Synder M, Wojciechowski M, Orczyk K, Jezierski H, Topol M, et al. Protective and Predisposing Morphological Factors in Suprascapular Nerve Entrapment Syndrome: A Fundamental Review Based on Recent Observations. Biomed Res Int. 2017;2017:4659761.

6. Deslaugiers B, Vaysse P, Combes JM, Guitard J, Moscovici J, Visentin M, et al. Contribution to the study of the tributaries and the termination of the external jugular vein. Surg Radiol Anat. 1994;16(2):173-7. 